\title{
Assessment of Foreign Body Aspiration Material Using a Virtual Bronchoscopy Model: Time-Density and Time-Volume Relationships
}

\author{
Tugay Tartar, ${ }^{1,}$ Unal Bakal, ${ }^{1}$ Mehmet Ruhi Onur, ${ }^{2}$ Mehmet Saraç, ${ }^{1}$ Ahmet Kürşad Poyraz, ${ }^{3}$ and Ahmet
}

Kazez $^{1}$

${ }^{1}$ Department of Pediatric Surgery, Firat University School of Medicine, 23119, Elazig, Turkey

${ }^{2}$ Department of Radiology, Hacettepe University School of Medicine, 06100, Ankara, Turkey

${ }^{3}$ Department of Radiology, Firat University School of Medicine, Elazig, Turkey

"Corresponding author: Tugay Tartar, Departments of Pediatric Surgery, Firat University School of Medicine, 23119, Elazig, Turkey. Tel: +90-4242333555, Fax: +90-4242388096 E-mail: tugaytartar@gmail.com

Received 2016 October 12; Revised 2016 November 17; Accepted 2016 December 14.

\begin{abstract}
Background: During foreign body aspiration (FBA), identifying the type of object is frequently problematic.

Objectives: This study assessed density changes over time in the most common organic, FBA materials using virtual bronchoscopy. We also examined volumetric changes in materials to determine the optimal removal time for each type of foreign body.

Materials and Methods: Size-appropriate slots for each type of foreign body were created on a $2 \times 30 \times 30 \mathrm{~cm}$ sponge plate. Objects (shelled and blanched peanuts, roasted chickpeas, hazelnuts, walnuts, almonds, pistachios, watermelon seeds, shelled and unshelled sunflower seeds, shelled and unshelled pumpkin seeds, chickpeas, beans, lemon seeds, and apple seeds) were placed into the slots, after which a second sponge, with identical dimensions, was placed over the top of the first sponge to achieve closure. A moist environment was maintained for 7 days at body temperature $\left(37^{\circ} \mathrm{C}\right)$. Multidetector computed tomography (MDCT) images of the sponges, volume and density measurements of objects performed each day were recorded. Intra-object differences in density and volume over time on MDCT were evaluated using time-density and time-volume curves, respectively. The SPSS for Windows software package (ver. 21.0; SPSS Inc., Chicago, IL, USA) was used to perform analyses. Pearson correlation analyses were used to determine differences in the volume and density of FBA materials across days. A time volumetric graph was also obtained. $\mathrm{P}<0.05$ was considered as significant.

Results: Following aspiration, organic material volumes on day 7 were below baseline values, although objects exhibited a 30\% average increase in volume during the first 4 days. The density values of objects increased between days 2 and 5 , and decreased thereafter.

Conclusions: Measuring daily changes in density allows for the identification of FBA materials. Our data indicate that object removal during days 1 -3, and on day 7 should be easier compared to days 4 - 6 .
\end{abstract}

Keywords: Foreign Body Aspiration, Virtual Bronchoscopy, Density, Volume

\section{Background}

Foreign body aspiration (FBA) is a serious clinical condition that can be fatal in pediatric patients. It is most common in males aged between 1-3 years (1-4). Medical history, physical examination, and imaging findings can facilitate diagnosis of FBA. In children, organic substances comprise $70 \%-80 \%$ of airway FBA materials. Such substances may rupture the capsule if swelling occurs due to environmental moisture, and may also be dispersed and spread during extraction by bronchoscopy $(1,2,4)$. Organic foreign bodies tend to remain in the body for a longer duration compared to inorganic substances due to their inert properties and radiolucent appearance, which cause delayed diagno$\operatorname{sis}(5)$.

Virtual bronchoscopy (VB) represents a noninvasive imaging technique that can be applied in suspected FBA with the cost of radiation risk. Although aspirated foreign bodies are detectable in the majority of cases, VB cannot determine the type of FBA $(2,4-7)$. Foreign bodies detected in airways are typically removed by bronchoscopy. Determining the type of foreign object, and optimal time for its removal affects the likelihood of a successful operation.

\section{Objectives}

In this study, our aim was to determine the volume and density changes in aspirated materials over time, and the optimal removal time for foreign bodies to increase the success of VB in pediatric cases of suspected FBA. 


\section{Materials and Methods}

\subsection{Study Design}

The study protocol was approved by the ethics committee of our institute. We implemented an experimental model similar to the body's internal environment, to investigate the behavior of organic foreign bodies in accordance with their volume and density. Two sponges $(2 \times 30 \times 30$ $\mathrm{cm}$ ) were used, with appropriately sized slots created on the lower sponge to accommodate shelled and blanched peanuts, roasted chickpeas, hazelnuts, walnuts, almonds, pistachios, watermelon seeds, shelled and unshelled sunflower and pumpkin seeds, chickpeas, beans, lemon seeds, and apple seeds (Figure 1). The sponge housing the objects was then covered with the other sponge, after which both were soaked in water and placed in a bain-marie to keep them moist at body temperature $\left(37^{\circ} \mathrm{C}\right)$ for 7 days. The density and volume of the various organic materials were measured and compared after daily scanning with multidetector computed tomography (MDCT) at regular intervals on day 1, 3, and 7 (day 3 was included in analyses because changes typically became apparent at this time). Density was measured in Hounsfield units (HU), and volume was measured in $\mathrm{cm}^{3}$.

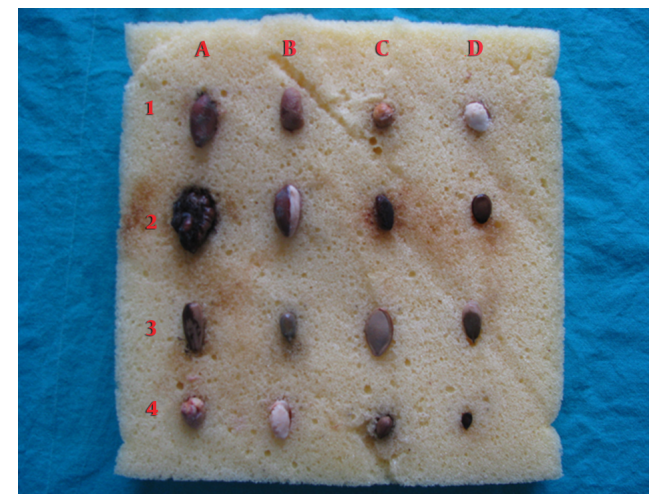

Figure 1. Placement of organic materials on sponge $\left(1^{\text {st }}\right.$ Place: $A$, Shelled peanuts; $B$, Blanched peanuts; C, Roasted chickpeas; D, Hazel nuts $2^{\text {nd }}$ Place: A, Walnuts; B, Almonds; C, Pistachios; D, Watermelon seeds $3^{\text {rd }}$ Place: A, Shelled sunflower seeds; B, Unshelled sunflower seeds; C, Shelled pumpkin seeds; D, Unshelled pumpkin seeds $4^{\text {th }}$ Place; A, Chickpeas; B, Beans; C, Lemon seeds; D, Apple seeds)

\subsection{Image Acquisition and Analysis}

MDCT was performed using a 64-slice $(0.5 \mathrm{~mm}$ slice thickness) scanner (Aquilion 64; Toshiba, Tokyo, Japan). CT images were reconstructed into axial, sagittal, and coronal planes using the OsiriX medical imaging software package (OsiriX, Atlanta, GA, USA), which was also used to measure the density and volume of each foreign body object. Density measurements were performed in three different areas for each substance and mean, minimum, and maximum density values of foreign bodies were recorded. Volume of the objects was measured by inserting circles, which confined the substance area on each CT slice (Figure 2). After measuring the area of the substance on each slice, the volume of each object was calculated automatically.

\subsection{Statistical Analysis}

The SPSS for Windows software package (ver. 21.0; SPSS Inc., Chicago, IL, USA) was used to perform statistical analyses. Pearson correlation analyses were used to determine differences in the volume and density values of FBA materials across days. A time volumetric graph was also obtained (Figure 3). $\mathrm{P}<0,05$ was considered as significant.

\section{Results}

No structural imperfections affected measurement of the volume or density of FBA materials on CT images. The density of nine foreign objects did not significantly change over the 7-day measurement period. In two of these objects (walnuts and pistachios), density was completely unchanged. In three others (shelled peanuts, apple, and peeled pumpkin seeds), density changed by 0 - $50 \mathrm{HU}$. In the remaining four objects (chickpeas, roasted chickpeas, beans, and lemon seeds) it changed by $>50$ HU (Table 1 ). Density value of the materials varied on a daily basis. Only in unshelled sunflower seeds, a statistically significant increase was observed in the density-time correlation analysis ( $\mathrm{r}$ : 0.843, P: 0.017). In the others, however, statistically insignificant changes were observed. Significant changes in density were observed for the remaining seven FBA materials, at all three recorded time periods (i.e., at 1, 3, and 7 days; Table 2). The mean daily densities of all FBA materials and density-time Pearson Correlations analysis results are listed in Table 3.

In the volume-time correlation analysis of organic materials, only almonds showed a statistically insignificant increase (r: 0.792, P: 0.034). In the others, however, statistically insignificant changes were observed (Table 4). In 12 FBA materials, volume decreased below baseline values by day 7. In the majority of cases, volumes were at their lowest on days 3 and 7 (Table 4 ).

\section{Discussion}

Despite its potential seriousness, FBA remains poorly understood. Therefore, increasing public awareness within childcare institutions, and among parents, is crucial. While early diagnosis in children is important, medical histories may not always be suggestive of FBA. In a 

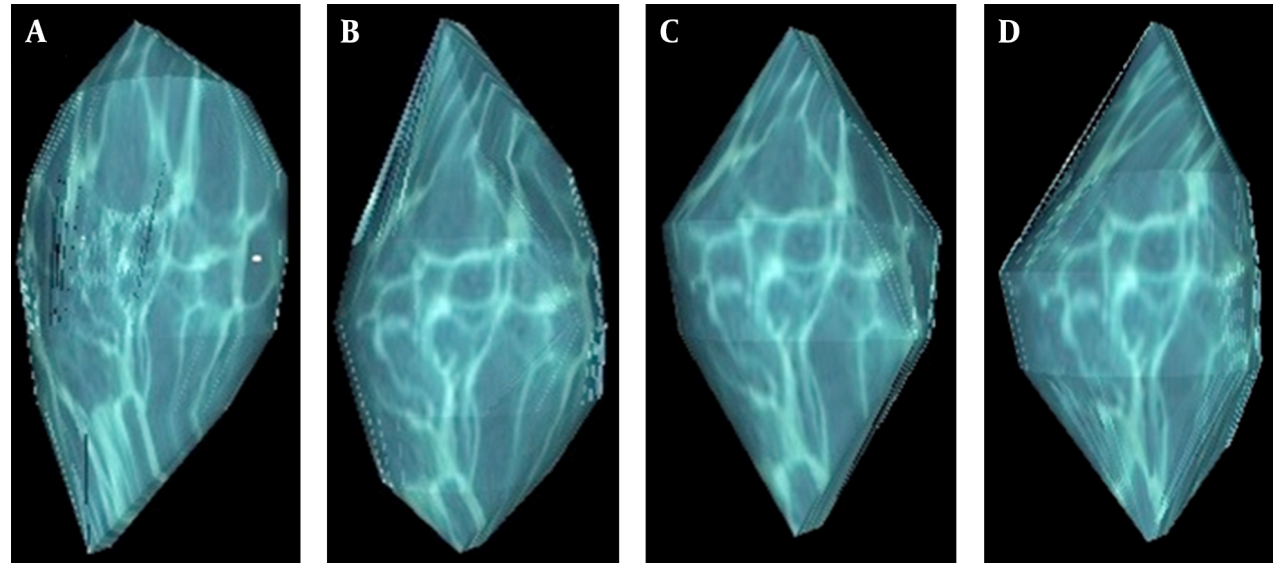

Figure 2. 3D Volume CT View of Foreign Bodies on the third day. A, Shelled peanuts; B, Blanched peanuts; C, Roasted chickpeas and D, Hazelnuts

A

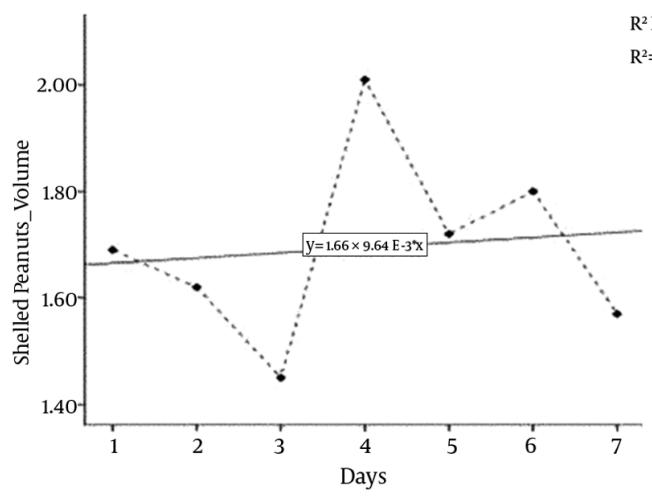

C

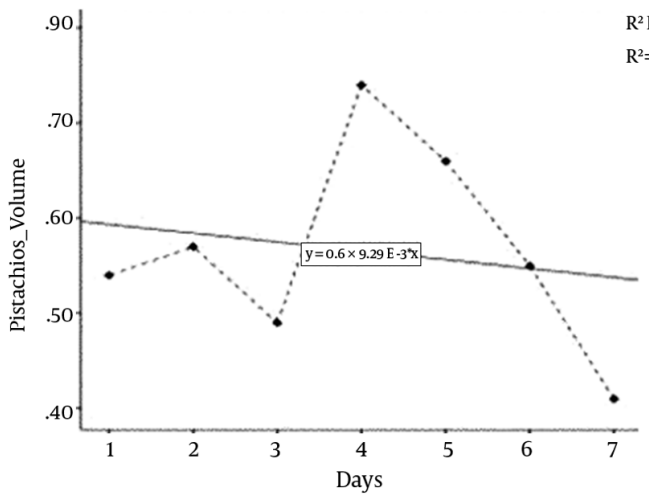

B

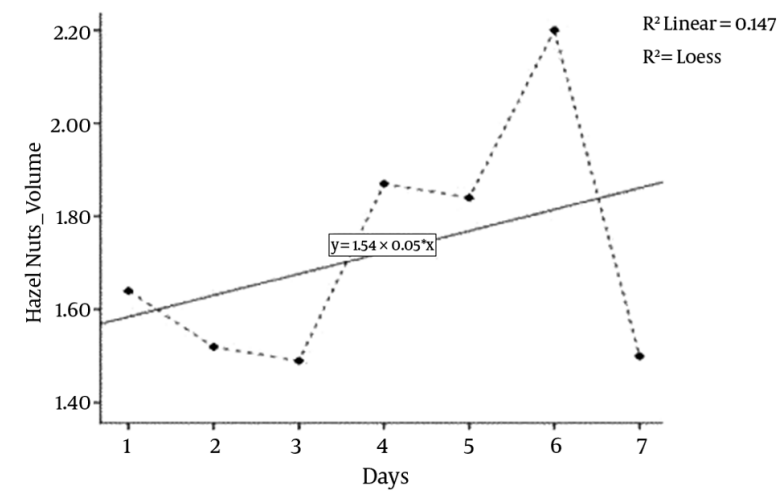

D

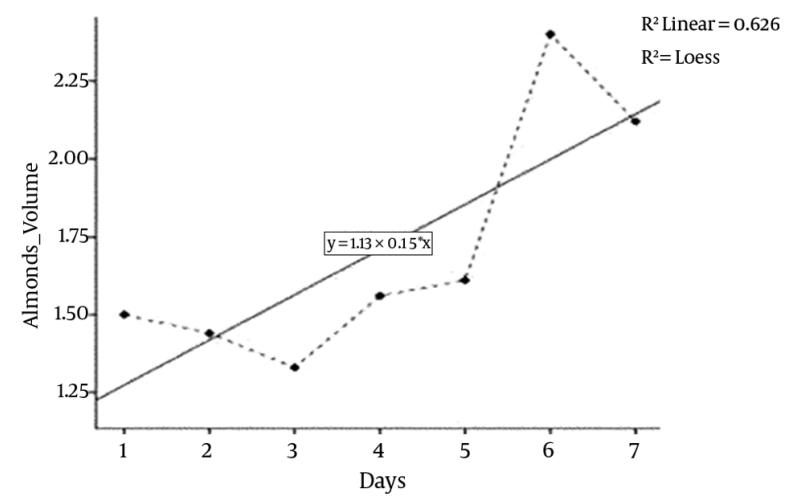

Figure 3. A Time Volumetric graph A, Shelled peanuts; B, Hazel nuts; C, Pistachios; D, Almonds

study conducted out of our clinic, the history of aspiration was negative in $28 \%$ of FBA patients (8). There are studies that indicate the cases are between $1 \mathrm{~h}$ and 10 years (9).
Rigid bronchoscopy represents the gold standard for the diagnosis and treatment of FBA. However, recognition of the potential utility of radiological techniques is in- 
Table 1. Organic Materials Without Significant Density Change

\begin{tabular}{lcll}
\hline Density Measurements, d & Density Value $<\mathbf{0 , H U}$ & Density Value $\mathbf{0}-\mathbf{5 0 , \text { HU }}$ & Density Value $>\mathbf{5 0 , \text { HU }}$ \\
\hline $\mathbf{1}^{\text {st }}$ & Walnuts pistachios & $\begin{array}{l}\text { Apple seeds, Shelled peanuts, Unshelled pumpkin } \\
\text { seeds }\end{array}$ & Chickpeas, Roasted chickpea, Beans, Lemon seeds \\
$\mathbf{3}^{\text {rd }}$ & Walnuts, pistachios & $\begin{array}{l}\text { Apple seeds, Shelled peanuts, Unshelled pumpkin } \\
\text { seeds }\end{array}$ & Chickpeas, Roasted chickpea, Beans, Lemon seeds \\
$7^{\text {th }}$ & Walnuts, pistachios & Apple core, Shelled peanuts, Unshelled pumpkin seeds & Chickpeas, Roasted chickpea, Beans, Lemon seeds \\
\hline
\end{tabular}

Table 2. Organic Materials with Significant Density Change

\begin{tabular}{lcll}
\hline Density Measurements, d & Density Value $<\mathbf{0 , \text { HU }}$ & Density Value 0 - 50, HU & Density Value $>\mathbf{5 0 , \text { HU }}$ \\
\hline $\mathbf{1}^{\text {st }}$ & $\begin{array}{c}\text { Hazelnuts, Watermelon seeds, Unshelled } \\
\text { sunflower seeds }\end{array}$ & $\begin{array}{l}\text { Almonds, Blanched peanuts, Shelled } \\
\text { pumpkin seeds, Shelled sunflower seeds }\end{array}$ \\
$\mathbf{3}^{\text {rd }}$ & Blanched peanuts & $\begin{array}{l}\text { Hazelnuts, Watermelon seeds, Unshelled } \\
\text { sunflower seeds }\end{array}$ & $\begin{array}{l}\text { Almonds, Shelled pumpkin seeds, Shelled } \\
\text { sunflower seeds }\end{array}$ \\
& Hazelnuts & $\begin{array}{l}\text { Almonds, Watermelon seeds, Blanched } \\
\text { peanuts, Shelled pumpkin seeds, Shelled } \\
\text { sunflower seeds, Unshelled sunflower } \\
\text { seeds }\end{array}$ \\
\hline
\end{tabular}

creasing, particularly because rigid bronchoscopy is an invasive procedure that must be performed under general anesthesia. Furthermore, foreign bodies are not always detected by rigid bronchoscopy, and there is no clear consensus on the optimal time at which the technique should be applied (although it is commonly believed that it must be conducted as soon as possible, with adjunctive treatment provided until the patient is in a condition conducive to the operation) (9). Early removal of foreign bodies by bronchoscopy is crucial since organic foreign bodies continue to grow in humid environments, which may cause an increased degree of obstruction followed by chemical pneumonia. Negative bronchoscopy results were observed in $16 \%$ of FBA cases $(2,10)$, which were thought to be responsible for a large proportion of all negative bronchoscopies.

In recent years, $\mathrm{VB}$, as a non-invasive, non-contrast used imaging technique has been recommended for detection of foreign bodies in the tracheobronchial tree due to its high diagnostic value $(11,12)$. Absence of aspiration history in $30 \%$ of FBA cases, nonobservation of $90 \%$ of aspirated foreign bodies on radiography due to nonopaque appearance of organic foreign bodies, lack of abnormal findings on chest radiographs in 16\% - 34\% of cases and probability of rigid bronchoscopy complications resulted in increased utility of VB in patients suspicious of FBA. Numerous studies have confirmed the diagnostic efficacy of $\mathrm{VB}$, which can detect $100 \%$ of foreign bodies in the bronchial tree $(8,13)$. In a study performed by Serap et al. (14), VB conducted before rigid bronchoscopy contributed to diagnosis of FBA and decreased negative bronchoscopy rates. Currently, there are no consensus criteria used to identify the type of FBA material, or to predict time period after aspiration. Standardized density data for frequently encountered organic foreign bodies in patients with FBA are also lacking. Given the lack of available data on the density of various organic materials in VB, our findings may be considered as reference data.

On day 4, volumetric changes were at their greatest extent for shelled peanuts, walnuts, pistachios, watermelon, apple, shelled sunflower seeds, shelled and peeled pumpkin seeds, beans, and apple seeds. The change in volume of lemon seeds was greatest on day 5, compared to day 6 for blanched peanuts, roasted chickpeas, hazelnuts, almonds, and chickpeas.

Among all types of foreign bodies, the greatest volumetric change occurred in apple seeds (130\%), followed by almonds (60\%), and lemon seeds (50\%). The majority of the objects increased between $15 \%$ and $40 \%$. in volume. The baseline volume of unshelled sunflower seeds also represented its highest value. The lowest recorded volumes recorded for all other objects were less than their baseline values. Organic materials tend to increase in size in a moisture-rich atmosphere, which may affect physical examination findings, possibly resulting in complete obstruction $(1,2,4,15,16)$. Furthermore, foreign bodies can precipitate inflammation, edema, and granulation formation after 3 days (17). In our study, the volume of each type of aspirated organic material did not increase consistently over time; instead, we observed variability across days, with 12 of the 16 types of objects exhibiting lower volumes on day 7 compared to baseline. Therefore, we suggest that aspirated organic materials alone cannot be respon- 
sible for all the changes typically observed during physical examination, or for complete obstruction in response to a moist environment. Foreign bodies may rather act in concert with edema and granulation tissue formation after day 3 to cause these effects.

Foreign objects should be most conducive to removal when they are at their minimum volume, and when patients are free of respiratory distress, in good general health (with stable vital signs and oxygen saturation within normal limits), and experiencing no type of withdrawal. Determination of appropriate time for removal of foreign bodies may affect success of the procedure.

Yildizeli et al. (17) reported a case in which a foreign body caused histological changes, including inflammation, edema, ulceration, and granulation on day 3, in addition to cartilage damage, bronchial dilation, and fibrosis after 1 month. We suggest that if a patient does not present to a hospital within 24 hours, shelled and blanched peanuts, hazelnuts, almonds, shelled and unshelled sunflower seeds, peeled pumpkin seeds, chickpeas, beans, and lemon seeds should be removed within 3 days by bronchoscopy. Furthermore, we suggest the removal of walnuts, pistachios, watermelon seeds, shelled pumpkin seeds, and apple seeds within 3 days. Although these objects do not reach their lowest volume until day 3 , the potential for histological changes thereafter necessitates earlier removal. In FBA patients with good general health, presenting to a clinic after $>3$ days with no respiratory distress and normal oxygen saturation, removal of shelled and blanched peanuts, roasted chickpeas, hazelnuts, walnuts, pistachios, shelled and unshelled sunflower seeds, shelled and peeled pumpkin seeds, chickpeas, beans, and lemon and apple seeds can be performed on day 7, at which time their volumes are lowest. It may be better to remove almonds on either day 5 or 7 .

On day 7, watermelon seeds, shelled sunflower and pumpkin seeds, and lemon and apple seeds were removed easily by forceps. We experienced more difficulty in removal of foreign bodies with strong capsules including shelled peanuts, walnuts, almonds, pistachios, unshelled sunflower seeds, peeled pumpkin seeds, chickpeas, and beans compared to shelled objects. However removal of foreign bodies with strong capsules was more easy than organic objects with a weak outer capsule. Furthermore, it was not possible to remove unshelled objects without an outer capsule (whole peanuts, roasted chickpeas, hazelnuts, walnuts, almonds, pistachios, sunflower and pumpkin seeds, chickpeas, and beans) in whole-form during a single attempt using forceps on day 7.

Our study had limitations. First, the in vitro model designed in our study may not represent an in vivo model due to mucus production, bronchospasm and effects of the immune system in the tracheobronchial tree, which may cause significant difference between the volume and density measurements of in vitro and in vivo models. Second, identifying density and volume changes of foreign bodies in the tracheobronchial tree cannot be used as the only decisive point in determining the time and method of endoscopic removal of the foreign body. Third, identification of the subtype of organic foreign bodies by measuring their daily density changes on VB is not possible. However, reference density values of most frequently aspirated foreign bodies may be helpful in predicting the nature of foreign bodies in patients before endoscopic removal. These reference values may also be helpful for further studies. Fourth, although the $7^{\text {th }}$ day seems to be more suitable for endoscopic removal of FBs due to volume decrease of FBs, timing of endoscopic removal should be determined with consideration of additional risk factors such as displacement of FB to a more critical location or more long standing complications.

In conclusion, even though the volumes and densities of the aspirated organic foreign bodies showed some changes compared to the first day, no significant correlation was found. However, it has been observed that the volume of foreign bodies has increased or decreased irregularly over time. In our opinion, the optimal time to apply VB, and the likely difficulty of removal, can be predicted by determining the type of object and time of aspiration. Although CT is not recommended for pediatric FBA, it could be useful when detection proves difficult.

\section{Acknowledgments}

This study was supported by the Department of Scientific Research Projects of our University (FUBAP Project No: TF.11.06/2013).

\section{Footnotes}

Authors' Contribution: None declared.

Conflict of Interest: The authors declare that they have no conflict of interests

Financial Disclosure: None declared.

Funding/Support: None declared.

\section{References}

1. Cutrone C, Pedruzzi B, Tava G, Emanuelli E, Barion U, Fischetto D, et al. The complimentary role of diagnostic and therapeutic endoscopy in foreign body aspiration in children. Int J Pediatr Otorhinolaryngol. 2011;75(12):1481-5. doi: 10.1016/j.ijporl.2011.08.014. [PubMed: 21924505]. 
2. Yıldırım M., Dogusoy I., Okay T. , Yasaroğlu M. , Demirbag H. , Aydemir B. . Tracheobronchial foreign bodies. Turkish J Thorac Cardiovasc Surg. 2003;11:228-31.

3. Foltran F, Ballali S, Passali FM, Kern E, Morra B, Passali GC, et al. Foreign bodies in the airways: a meta-analysis of published papers. Int J Pediatr Otorhinolaryngol. 2012;76 Suppl 1:S12-9. doi: 10.1016/j.ijporl.2012.02.004. [PubMed: 22333317].

4. Boufersaoui A, Smati L, Benhalla KN, Boukari R, Smail S, Anik $\mathrm{K}$, et al. Foreign body aspiration in children: experience from 2624 patients. Int J Pediatr Otorhinolaryngol. 2013;77(10):1683-8. doi: 10.1016/j.ijporl.2013.07.026. [PubMed: 23962764].

5. Tokar B, Ozkan R, Ilhan H. Tracheobronchial foreign bodies in children: importance of accurate history and plain chest radiography in delayed presentation. Clin Radiol. 2004;59(7):609-15. doi: 10.1016/j.crad.2004.01.006. [PubMed: 15208067].

6. Tuncer U, Soylu L, Aydogan B, Ozsahİnoglu C, Tarkan O. Laringotrakeo-bronșial yabancı cisim aspirasyonu: 182 olgunun retrospektif İncelenmesi. Turkiye Klinikleri J Med Sci. 2002;2(2):95-9.

7. Black RE, Johnson DG, Matlak ME. Bronchoscopic removal of aspirated foreign bodies in children. J Pediatr Surg. 1994;29(5):682-4. doi: 10.1016/0022-3468(94)90740-4.

8. Tartar T, Kazez A, Onur MR, Poyraz AK, Sarac M, Bakal U. Experience with virtual bronchoscopy in children with foreign body aspiration. J Turkish Assoc Pediatr Surg. 2010;24:77-81.

9. Pekcan S, Aslan AT. Foreign body aspiration in childhood. Turkish J Pediatr Dis. 2010;4:119-28.

10. Kolbakir F, Keceligil TH, Ankan A, Erk KM. Removal of foreign bodies from tracheobroncheal tree analyses of 152 cases. Turkish J ThoracCardiovasc Surg. 1995;3:117-20.
11. Choi YW, McAdams HP, Jeon SC, Park CK, Lee SJ, Kim BS, et al. Low-dose spiral ct: Application to surface-rendered three-dimensional imaging of central airways. J Comput Asist Tomogr. 2002;26(3):335-41. doi: 10.1097/00004728-200205000-00003.

12. Lam WW, Tam PK, Chan FL, Chan KL, Cheng W. Esophageal atresia and tracheal stenosis: use of three-dimensional CT and virtual bronchoscopy in neonates, infants, and children. AJR Am J Roentgenol. 2000;174(4):1009-12. doi: 10.2214/ajr.174.4.1741009. [PubMed: 10749240].

13. Haliloglu M, Ciftci AO, Oto A, Gumus B, Tanyel FC, Senocak ME, et al. CT virtual bronchoscopy in the evaluation of children with suspected foreign body aspiration. Eur J Radiol. 2003;48(2):188-92. doi: 10.1016/s0720-048x(02)00295-4.

14. Dogan S, Coskun A, Yikilmaz A, Hasdiraz L, Tahan F. The value of lowdose multidetector CT and virtual bronchoscopy findings in pediatric patients with suspected foreign body aspiration. Erciyes Tip Dergisi. 2008;30(2):78-83.

15. Pașaoĝlu I, Doĝan R, Demircin M, Hatipoĝlu A, Bozer A. Bronchoscopic removal of foreign bodies in children: Retrospective analysis of 822 cases. J Thorac Cardiovasc Surg. 2008;39(02):95-8. doi: 10.1055/s-20071013940.

16. Kaptanoglu M, Nadir A, Dogan K, Sahin E. The heterodox nature of "Turban Pins" in foreign body aspiration; the central anatolian experience. Int J Pediatr Otorhinolaryngol. 2007;71(4):553-8. doi: 10.1016/j.ijporl.2006.11.017. [PubMed: 17224190].

17. Yildizeli B, Zonuzi F, Yuksel M, Kodalli N, Cakalagaoglu F, Kullu S. Effects of intrabronchial foreign body retention. Pediatr Pulmonol. 2002;33(5):362-7. [PubMed: 11948981]. 


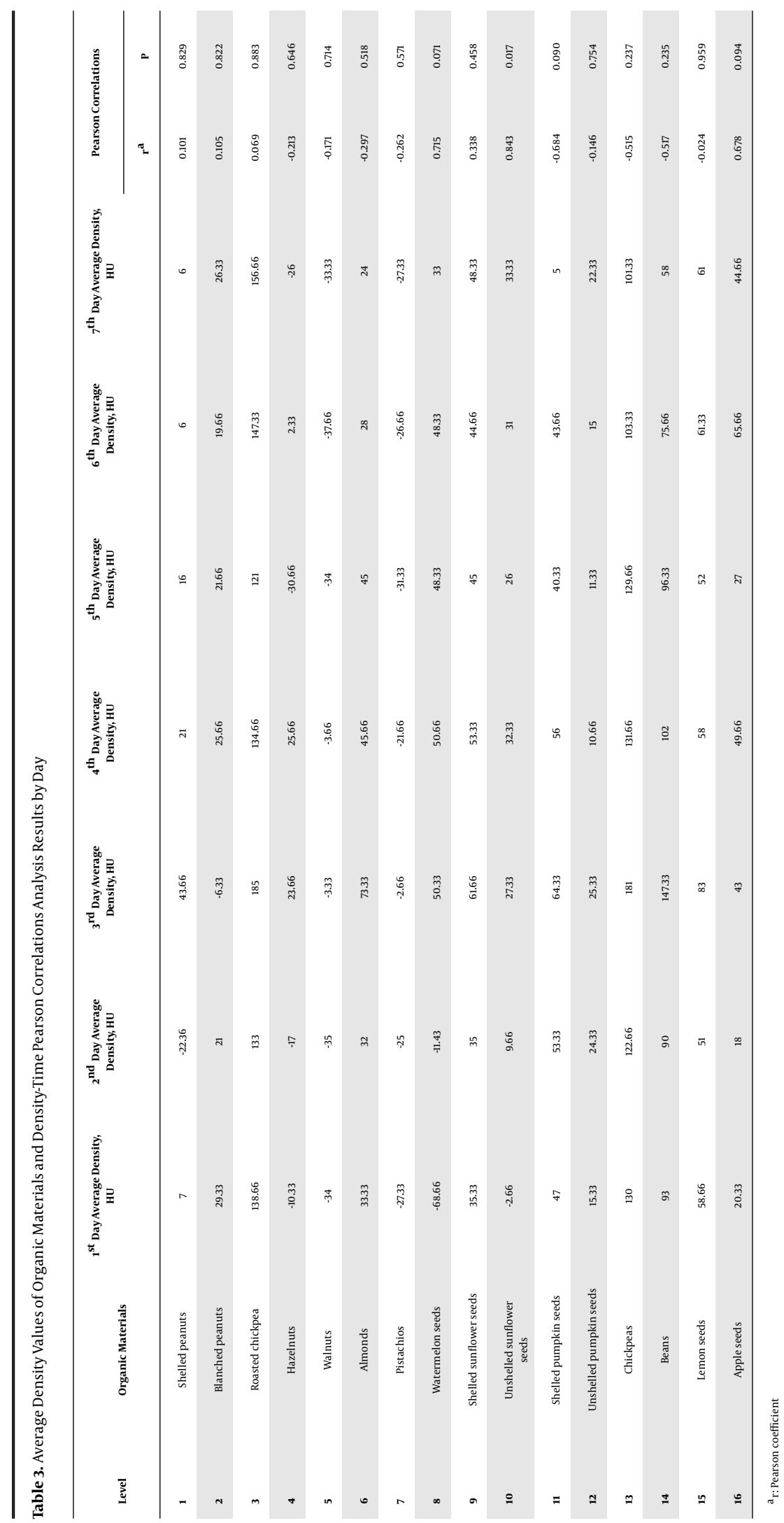




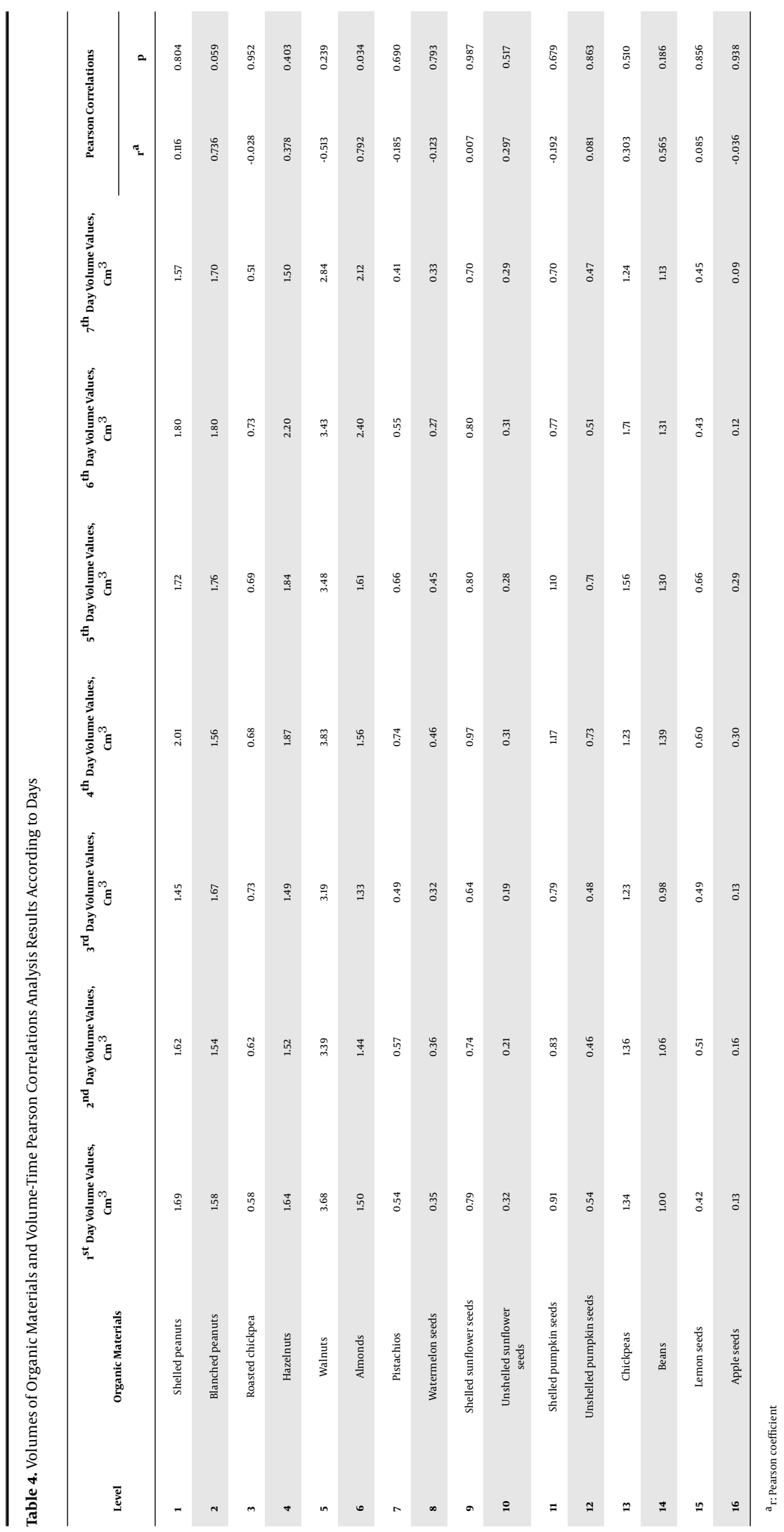

